\title{
Apolipoprotein epsilon 3 alleles are associated with indicators of neuronal resilience
}

\author{
Orwa Aboud ${ }^{1,3}$, Robert E Mrak ${ }^{4}$, Frederick Boop ${ }^{5}$ and Sue T Griffin ${ }^{1,2,3^{*}}$
}

\begin{abstract}
Background: Epilepsy is associated with precocious development of Alzheimer-type neuropathological changes, including appearance of senile plaques, neuronal loss and glial activation. As inheritance of APOE $\varepsilon 4$ allele(s) is reported to favor this outcome, we sought to investigate neuronal and glial responses that differ according to $A P O E$ genotype. With an eye toward defining ways in which APOE $\varepsilon 3$ alleles may foster neuronal well-being in epilepsy and/or $A P O E \& 4$ alleles exacerbate neuronal decline, neuronal and glial characteristics were studied in temporal lobectomy specimens from epilepsy patients of either APOE $\varepsilon 4,4$ or $A P O E \varepsilon 3,3$ genotype.
\end{abstract}

Methods: Tissue and/or cellular expressions of interleukin-1 alpha (IL-1 $\alpha$ ), apolipoprotein $E$ (ApoE), amyloid $\beta$ (A $\beta$ ) precursor protein ( $\beta A P P)$, synaptophysin, phosphorylated tau, and $A \beta$ were determined in frozen and paraffinembedded tissues from 52 APOE $\varepsilon 3,3$ and 7 APOE $\varepsilon 4,4$ ( 0.25 to 71 years) epilepsy patients, and 5 neurologically normal patients using Western blot, RT-PCR, and fluorescence immunohistochemistry.

Results: Tissue levels of IL-1 $\alpha$ were elevated in patients of both APOE $\varepsilon 3,3$ and APOE $\varepsilon 4,4$ genotypes, and this elevation was apparent as an increase in the number of activated microglia per neuron (APOE $\varepsilon 3,3$ VS APOE $\varepsilon 4,4=$ $3.7 \pm 1.2$ vs $1.5 \pm 0.4 ; P<0.05$ ). This, together with increases in $\beta A P P$ and $A p o E$, was associated with apparent neuronal sparing in that $A P O E \varepsilon 4,4$ genotype was associated with smaller neuron size (APOE $\varepsilon 4,4$ vs $A P O E \varepsilon 3,3=$ $173 \pm 27$ vs $356 \pm 45 ; P \leq 0.01)$ and greater DNA damage (APOE $\varepsilon 4,4$ vs APOE $\varepsilon 3,3=67 \pm 10$ vs $39 \pm 2 ; P=0.01)$. 3) $A \beta$ plaques were noted at early ages in our epilepsy patients, regardless of $A P O E$ genotype (APOE $\varepsilon 4,4$ age 10 ; APOE $\varepsilon 3,3$ age 17).

Conclusions: Our findings of neuronal and glial events, which correlate with lesser neuronal DNA damage and larger, more robust neurons in epilepsy patients of APOE $\varepsilon 3,3$ genotype compared to APOE $\varepsilon 4,4$ genotype carriers, are consistent with the idea that the APOE $\varepsilon 3,3$ genotype better protects neurons subjected to the hyperexcitability of epilepsy and thus confers less risk of AD (Alzheimer's disease).

Please see related article: http://www.biomedcentral.com/1741-7015/10/36

Keywords: Amyloid beta (Aß?ß?), Alzheimer disease, APOE genotype, DNA damage, epilepsy, interleukin-1, neuroinflammation, phosphorylated tau, synaptophysin, TUNEL

\section{Background}

Epilepsy is associated with precocious development of Alzheimer-type neuropathological changes, and the $A P O E \& 4$ genotype has been associated with further risk of development of such changes [1,2]. A role for glial activation with excess expression of cytokines in epilepsy pathogenesis was first recognized as enlargement of

\footnotetext{
* Correspondence: griffinsuet@uams.edu

'Donald W. Reynolds Department of Geriatrics, Reynolds Institute on Aging, 629 Jack Stephens Drive, Little Rock, AR 72205, USA

Full list of author information is available at the end of the article
}

microglia and astrocytes with overexpression of IL-1 and S100B, respectively [3-5]. Such findings gave rise to a new understanding of the role of glial activation and overexpression of cytokines as potential precursors of neurodegenerative change, including $A \beta$ plaques and neurofibrillary tangles [6]. These findings are consistent with the idea that glia-related neuroinflammatory events are early contributors to epilepsy pathogenesis.

Neuronal stress, such as the hyperexcitability induced by glutamate in epilepsy, elevates neuronal expression of $\beta A P P$ and release of sAPP, which activates microglia and

\section{Biomed Central}


induces excess IL-1 production. This elevation in IL-1 production is attenuated by ApoE 3, but not ApoE 4 [7]. In turn, IL-1 induces further neuronal expression of $\beta$ APP and SAPP leading to further microglial activation and further release of IL-1 [8]. IL-1 also induces neuronal expression of ApoE [9], which in turn induces further expression of $\beta$ APP in an ApoE isoform-dependent manner; with ApoE3 more effective than ApoE4 [10].

A great deal of research has been dedicated to understanding how and why the presence of an $A P O E \& 4$ allele(s) is so strongly associated with negative outcomes in neurological conditions, such as head injury [11]. Here, rather than taking this tack, we chose to investigate the potential for beneficial effects conferred by $A P O E \& 3$ alleles due to their neuroprotective potential. Tissue samples from temporal lobes resected from epilepsy patients carrying two $A P O E \& 3$ alleles were examined regarding an association between inheritance of these alleles and determinants of neuronal resilience. These determinants included the ability of neurons to mount appropriate acute phase responses, including increases in $\beta \mathrm{APP}$ and ApoE, as well as management of DNA damage, maintenance of morphological integrity and glial activation. Our findings indicate that the $A P O E$ $\varepsilon 3,3$ genotype confers a neuroprotective advantage over the $A P O E \& 4,4$ genotype, in the setting of intractable epilepsy with its accompanying hyperexcitability-induced neuronal damage, glial activation and excessive expression of the proinflammatory cytokine IL-1 $\alpha$.

\section{Methods}

\section{Patients and specimens}

Resected temporal lobe tissues were obtained from 95 epilepsy patients; of those 59 were included in this study (39 males and 20 females; 52 APOE $\varepsilon 3,3$ and 7 APOE $\varepsilon 4,4)$ with an age at surgery ranging from 0.25 to 71 years. Analyses of surgical waste remains from temporal lobectomy surgeries to treat intractable, drug-resistant epilepsy were compared to those of autopsy samples from neurologically normal individuals brought to autopsy for reasons other than this study. Both surgical waste and autopsy tissue are exempt under 46.101 5(b) and approved by our University of Arkansas Institutional Review Board.

All patients underwent anterior temporal lobectomy for treatment of medication-resistant intractable epilepsy. Tissue was sectioned at $4 \mathrm{~mm}$ intervals and alternate sections were preserved by flash freezing for molecular analyses and by formalin fixation for histological evaluation. Preliminary immunohistochemical analysis was performed on all epilepsy cases, and a smaller group was selected for further investigation. Six $A P O E$ $\varepsilon 3,3$ cases (five males and one female, ages $18,24,38$, 44, 67 and 57 years, respectively) and four $A P O E \& 4,4$ cases (three males and one female, ages 10, 22, 50 and 34 , respectively) were selected for more extensive analyses, based on age in the case of $A P O E \varepsilon 3,3$ patients, and with regard to availability of sufficient frozen tissue for molecular analyses among APOE \&4,4 patients. Sufficient frozen tissue and fixed tissue was available for both immunohistochemical and molecular analyses of four $A P O E \& 4,4$ patients (three males and one female, ages as above). For uniformity, immunohistochemical examination was restricted to cortical layers III, IV, V and VI of the superior temporal lobe. For comparison of results from our $A P O E \& 3,3$ and $A P O E$ \&4,4 genotype patients, analogous temporal lobe tissues from neurologically normal individuals of varying $A P O E$ genotype and at older ages (four males and one female, ages 71, $97,59,50$ and 93 years) were assessed. This selection was based on the premise that individuals with pre-AD (Alzheimer's disease) or with AD at these ages would have plaques.

\section{Reagents}

The antibodies used were as follows: rabbit anti-human IL-1 $\alpha$ (Peprotech, Rocky Hill, NJ, USA, 4:1,000); goat anti-human APOE (Life Technology, Grand Island, NY, USA, 1:50); mouse anti-human A $\beta / \beta$ APP (Covance, Denver, CO, USA, 1:1,000); rabbit anti-synaptophysin (Abcam, Cambridge, MA, USA, 1:1,000); rabbit antiphosphorylated tau (Abcam 1:3,000); rabbit anti-actin (Santa Cruz Biotechnology, Santa Cruz, CA, USA, 1:5,000) were diluted in antibody diluent (DAKO, Carpenteria, CA, USA), and Iba-1 (WAKO, Richmond, VA, USA,1:400). Mounting media containing Prolong Gold antifade reagent with DAPI (Life Technologies) was used to stain nuclei.

\section{Immunohistochemistry}

Paraffin-embedded tissue was sectioned at $7 \mu \mathrm{m}$, deparaffinized in xylene and rehydrated in graduated ethanol solutions to deionized water. Sections for IL- $1 \alpha$ immunoreaction were placed in boiling sodium citrate buffer (0.01 M, pH 6.0) for 20 minutes; sections for $\beta$ APP and ApoE were placed in trypsin solution for 10 minutes at $37^{\circ} \mathrm{C}$, and all were blocked using protein block (DAKO), and incubated overnight at room temperature. Secondary antibodies, Alexa Fluor donkey anti-goat and donkey anti-rabbit were diluted in antibody diluent (DAKO) and sections were incubated for 60 minutes, washed three times for 5 minutes each in distilled $\mathrm{H}_{2} \mathrm{O}$, and coverslipped with prolong Gold with DAPI.

\section{Plaque analysis}

Plaques were identified by the simultaneous presence of ApoE and $A \beta$ immunoreactivity. The number of plaques in 10 consecutive $20 \mathrm{X}$ images $\left(0.37 \mathrm{~mm}^{2}\right)$ from sections 
of tissue from each patient was enumerated. Plaque phase was based on Braak and Braak staging of $A \beta$ plaques [12] and estimated with regard to our experience with such estimation in Alzheimer tissue.

\section{Image analysis}

Similar to a previous study [10], a quantitative approach was used to examine the number of glia and neurons. Three images per slide (40X magnification) were captured at identical exposure settings, using a Nikon Eclipse E600 microscope (Melville, NY, USA) equipped with a Coolsnap ES monochrome camera (Photometrics, Tucson, AZ, USA). Each of the three images, spanning $37,241.5 \mu \mathrm{m}^{2}$, was acquired and analyzed using NIS-Elements BR3 software http://Nikon.com and thresholded. Only microglia immediately adjacent to neuron somas were counted. Data were analyzed by ANOVA to assess difference among groups. Significance was provided by $P \leq 0.05$.

\section{Reverse transcription (RT) reaction and polymerase chain reaction (PCR) amplification}

Total RNA was extracted from brain tissue using TriReagent $^{\mathrm{TM}}$ RNA (Molecular Research Center, Cincinnati, $\mathrm{OH}$, USA) according to the manufacturer's instructions. RTPCR was performed as previously described [9]. Briefly, for comparisons of mRNA levels among different RNA samples, RT reactions were performed simultaneously using reagents from a single master mix. PCR was performed using reagents from Clontech (Mountain View, CA, USA). The sequences of primers for human IL-1 $\alpha$ and GAPDH, amplification cycles and annealing temperature are provided in Table 1 . PCR reactions were stopped by incubation for 10 minutes at $72^{\circ} \mathrm{C}$. Equal volumes of reaction mixture from each sample were loaded onto $1.2 \%$ agarose gels, and fluorescent images were digitally captured for analysis of intensity with $\mathrm{NIH}$ Image software 1.60 version http://rsbweb.nih.gov/nih-image/. Levels of IL-1 $\alpha$ were normalized relative to GAPDH in the same sample.

\begin{tabular}{|c|c|c|c|}
\hline $\begin{array}{l}\text { Gene } \\
\text { analyzed }\end{array}$ & $\begin{array}{l}\text { Human } \\
\text { sequences }\end{array}$ & $\begin{array}{l}\text { Annealing } \\
\text { temp. }\left({ }^{\circ} \mathrm{C}\right)\end{array}$ & $\begin{array}{l}\text { Cycle } \\
\text { no. }\end{array}$ \\
\hline \multicolumn{4}{|c|}{$\overline{\text { Gel-based PCR }}$} \\
\hline \multirow[t]{2}{*}{$\mathrm{IL}-1 \alpha$} & F: AAG CCT TCC TGC CGC AAC & 57 & 32 \\
\hline & $\begin{array}{l}\text { R: CTG CAC CTA CCA AAC ACG } \\
\text { G }\end{array}$ & & \\
\hline \multirow[t]{2}{*}{ GAPDH } & $\begin{array}{l}\text { F: AGG TCG GAG TCA ACG GAT } \\
T T G\end{array}$ & 57 & 32 \\
\hline & $\begin{array}{l}\text { R: TGG CAG GTT TाT CTA GAC } \\
\text { GGC }\end{array}$ & & \\
\hline
\end{tabular}

\section{Western immunoblot assay}

Proteins were extracted from brain tissue in a lysis buffer comprising $20 \mathrm{mM}$ Tris- $\mathrm{HCl}$ (pH 7.5), $150 \mathrm{mM} \mathrm{NaCl}, 1 \%$ Nonidet P40, 1 mM EGTA, 1 mM EDTA and 1\% sodium deoxycholate; lysates were quantified using a Micro BCA assay reagent kit (Pierce, Rockford, IL, USA) as described previously [13]. Aliquots (50 $\mu$ g each) were loaded onto 4 to $12 \%$ Criterion $^{\mathrm{XT}}$ precast Gels (Biorad, Hercules, CA, USA, Catalog \# 345-0123), subjected to electrophoresis at $90 \mathrm{~V}$ for $1.5 \mathrm{~h}$, and transferred to nitrocellulose membranes. Blots were blocked in I-Block Buffer (Applied Biosystem Inc., Bedford, MA, USA) for 60 minutes, then incubated overnight at $4{ }^{\circ} \mathrm{C}$ with either goat polyclonal antibody anti-IL- $\alpha$ (Santa Cruz Biotechnology 1:500), mouse anti-human $\mathrm{A} \beta / \beta \mathrm{APP}$ (Covance $1: 1,000$ ), rabbit anti-synaptophysin (Abcam 1:1,000), rabbit anti-phosphorylated tau (Abcam 1:3,000), or rabbit anti-actin (Santa Cruz Biotechnology 1:5,000); the latter of which was used here for calculating the relative levels of the other proteins assessed by western blot analyses. Membranes were then incubated for $1 \mathrm{~h}$ at room temperature with alkaline phosphatase-conjugated secondary antibody and developed using the Western-Light ${ }^{\mathrm{TM}}$ Chemiluminescent Detection System (Applied Biosystem Inc., Bedford, MA, USA). Autoradiographs were digitized and analyzed using NIH Image software, version 1.60.

\section{TUNEL staining procedure}

For terminal deoxynucleotidyl transferase dUTP nick end labeling (TUNEL) (NeuroTacs Kit, 4823-30-K, Trevigen, Gaithersburg, MD, USA) reactions, rehydrated sections were permeablized with NeuroPore ${ }^{\circledR}$ for 30 minutes at room temperature, washed in PBS buffer, placed in TdT labeling buffer for 5 minutes, treated with the labeling reaction mix (TdT dNTP, $50 \times \mathrm{Mn}^{+2}$, and TdT Enzyme) for 60 minutes at $37^{\circ} \mathrm{C}$ followed by stop buffer for 5 minutes, then streptavidin AF 594 conjugate (Invitrogen, S32356) for 10 minutes at room temperature. The sections were then treated with $0.1 \%$ Sudan black B in $70 \%$ ethanol for two minutes to block lipofuscin autofluorescence, washed in three changes of distilled $\mathrm{H}_{2} \mathrm{O}$, five minutes each; and coverslipped with Prolong Gold with DAPI.

\section{Statistical analysis}

Data were analyzed using an unpaired $t$-test, and values were considered significantly different when the $P$-value was $\leq 0.05$. Results are expressed as mean $\pm \mathrm{SD}$.

\section{Results}

Numbers of IL- $1 \alpha$-immunoreactive microglia per neuron are $A P O E$ genotype-dependent

An initial screening of 59 epilepsy patients (52 APOE $\varepsilon 3,3 ; 7$ APOE $\varepsilon 4,4)$ and 5 neurologically normal controls 
revealed an observable elevation in numbers of microglia per neuron soma in brain tissue from epilepsy patients compared to that in brain tissue from controls (data not shown). A smaller group of age-matched patients with either $A P O E \varepsilon 3,3(\mathrm{n}=6)$ or $A P O E \& 4,4(\mathrm{n}=4)$ genotype was chosen for further analysis to determine if this increase in numbers of IL- $1 \alpha$ immunoreactive microglia (Iba-1-immunoreactive) per ApoE-immunoreactive neuron segregated according to $A P O E$ genotype. Numbers as high as $8 \mathrm{IL}-1 \alpha / \mathrm{Iba}-1$-immunoreactive microglia were noted clustered immediately adjacent to individual ApoE-immunoreactive neurons in $A P O E$ \&3,3 patients (Figure 1A) compared to a maximum of three microglia per neuron in $A P O E \& 4,4$ patients (Figure $1 \mathrm{~B}$ ). Overall, $A P O E \& 3,3$ neurons had twice as many associated microglia as did $A P O E \& 4,4$ neurons $(3.7 \pm 1.2$ vs $1.5 \pm 0.4 ; P$ $<0.01$ ) (Figure $1 C$ ). As to the total number of microglia per $0.037 \mathrm{~mm}^{2}$ in tissue from epilepsy patients with $A P O E \& 3,3$ vs $A P O E \& 4,4$ genotype $(37.2 \pm 10.6$ vs $23 \pm$ 5.7; $P<0.05)$.

\section{Neuron number and size with regard to $A P O E$ genotype}

To assess the consequences of epilepsy and $A P O E$ genotype on neurons, we counted neurons in cortical layers III to VI of three specific areas of the temporal lobe. By histological inspection, changes in the appearance of individual neurons were evident, with the distinguishing feature being an $A P O E \quad 4,4$ genotype-associated decrease in size of both the cytoplasm and nucleus (Figure $2 \mathrm{~A}, \mathrm{~B})$. When quantified, this general impression correlated with a genotype-related difference in neuronal size. The average size of neurons in patients with $A P O E$ $\varepsilon 4,4$, was smaller than in patients with $A P O E \varepsilon 3,3$ (173 \pm 27 vs $356 \pm 45 \mu^{2} ; P<0.001$ ) (Figure $2 \mathrm{C}, \mathrm{D}$ ), but the numbers of neurons were not different in cortical layers of patients with $A P O E \varepsilon 4,4$ and $A P O E \varepsilon 3,3$ genotypes $(24 \pm 2$ vs $22 \pm 3 ; P=0.18$ ) (Figure $2 \mathrm{E}, \mathrm{F})$,.

\section{Neuronal DNA damage is related to APOE genotype}

DNA damage was present in similar numbers of neurons in analogous areas of the temporal lobe, without regard to $A P O E$ genotype (Figure $3 \mathrm{~A}, \mathrm{C}$ ). However, the extent of damage per neuron, as assessed by TUNEL fluorescence intensity, was greater in patients with $A P O E \& 4,4$ than with $A P O E \varepsilon 3,3$ genotype (67 \pm 10 vs $39 \pm 2 ; P=0.01$ ) (Figure $3 \mathrm{~B}, \mathrm{D}$ ).

\section{$\beta A P P$ tissue levels as a function of IL- $1 \alpha$ expression and APOE genotype}

The increased numbers of microglia per neuron noted in $A P O E \& 3,3$ vs $A P O E \& 4,4$ patients were reflected at the level of IL-1 $\alpha$ synthesis and production. Overall, levels of IL- $1 \alpha$ mRNA were elevated within a group of 10 of our epilepsy patients with various combinations of $A P O E \& 2, A P O E \varepsilon 3$, or $A P O E \& 4$ alleles compared to levels in control patients (Figure 4A), although one patient with $A P O E \& 4,4$ genotype had mRNA levels that were not different from that of control patients (Figure $4 B)$. Overall, patients with epilepsy had IL-1 $\alpha$ mRNA levels that were five-fold higher than those of
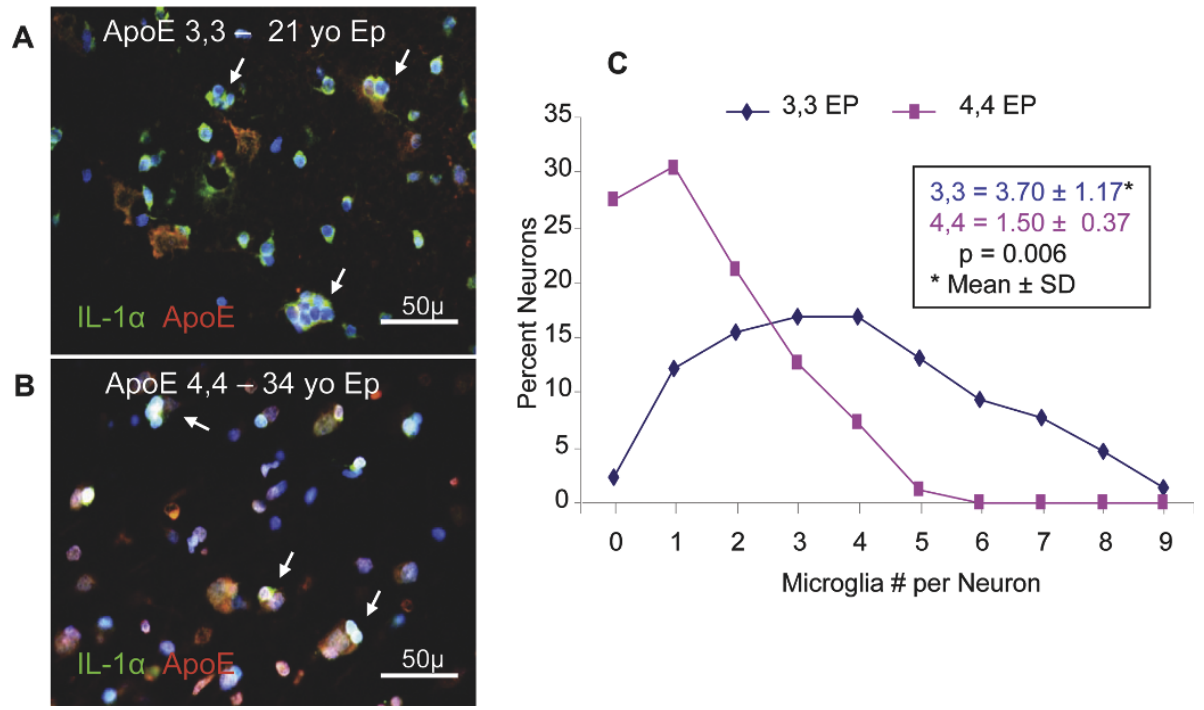

Figure 1 Microglial numbers per neuron in epilepsy relative to APOE genotype IL-1 $\alpha$-immunoreactive microglia (green) clustered around individual ApoE-immunoreactive neuron soma (red) in a 21-year-old $A P O E \varepsilon 3,3$ (A) and a 34-year-old $A P O E \varepsilon 4,4$ (B) patient. $A$ maximum of 8 microglia per neuron were present in $A P O E \varepsilon 3,3$ patients compared to four or fewer in $A P O E \varepsilon 4,4$ patients (C). Overall, $A P O E \varepsilon 3,3$ patients had twice as many microglia per neuron as did APOE $\varepsilon 4,4$ patients. Nuclei were stained with DAPI (blue). White arrows denote neurons with microglia. 

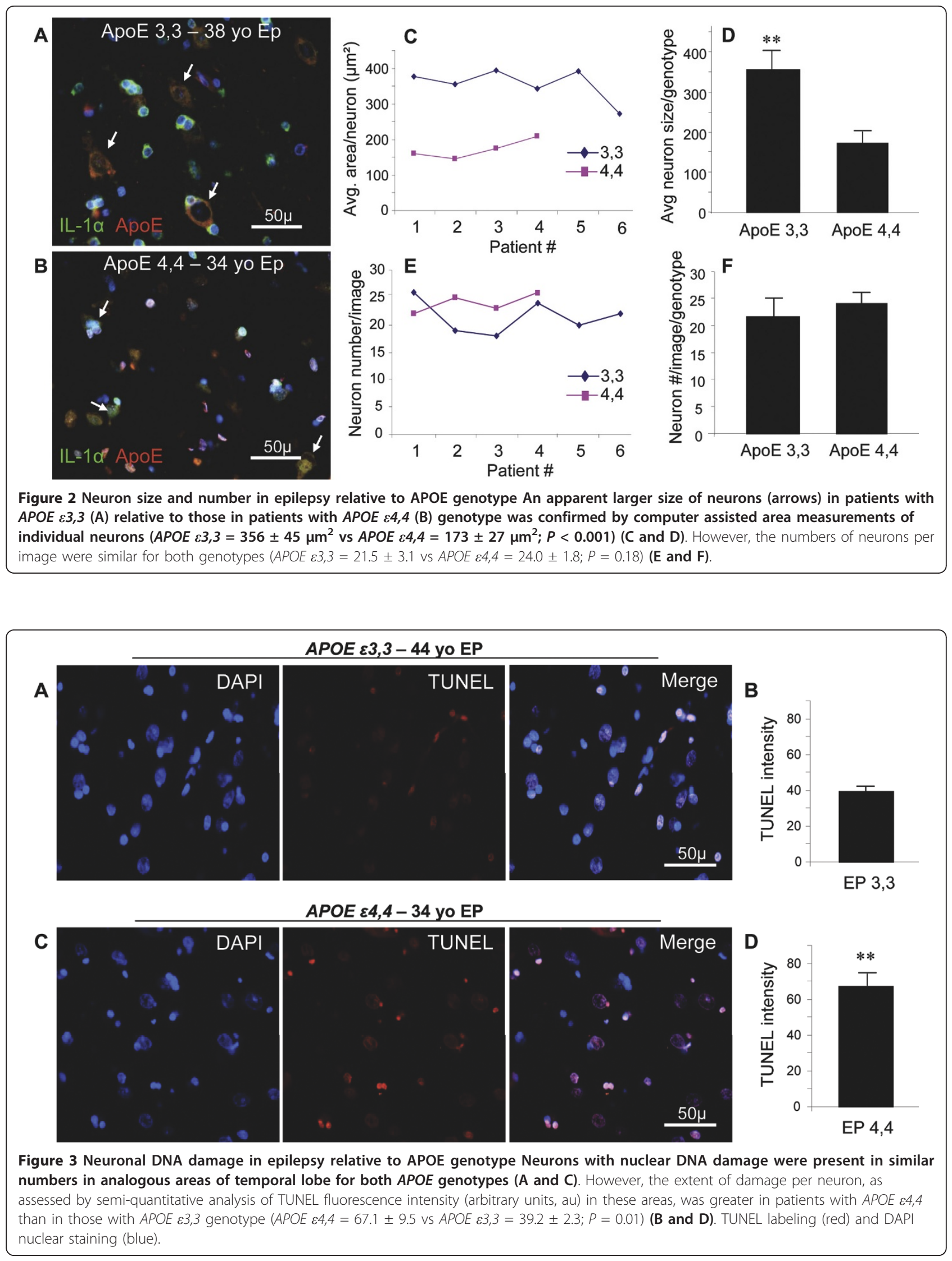
A

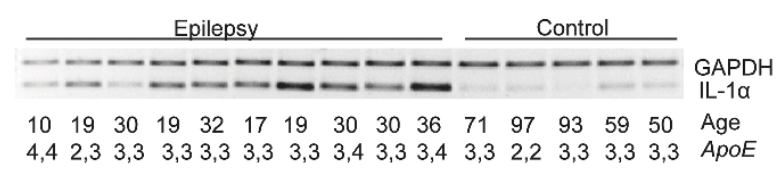

C

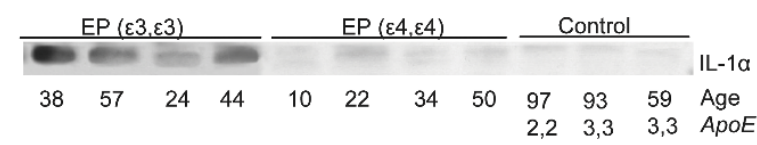

E

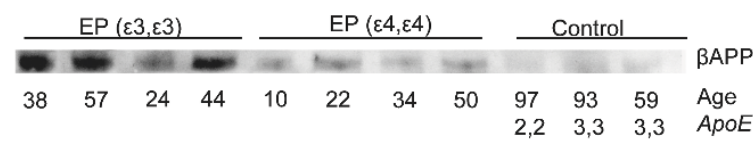

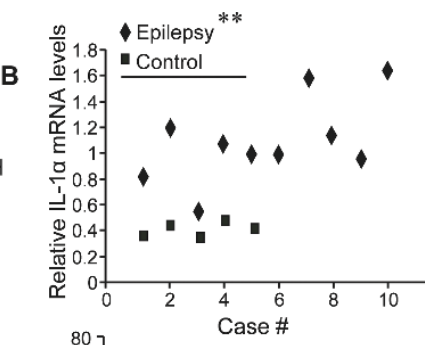

D

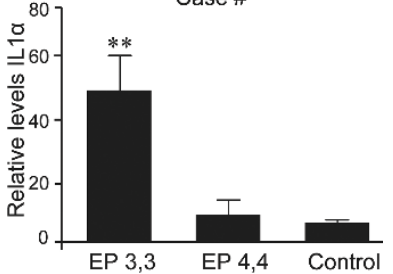

$\mathbf{F}$

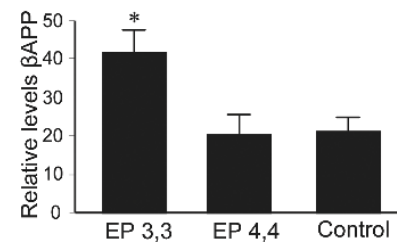

Figure 4 Neural cell acute phase responses in epilepsy relative to APOE genotype IL-1 $\alpha$ mRNA levels in temporal lobe tissue from epilepsy patients were elevated compared to levels in control patients (A). With the exception of one patient with APOE $\varepsilon 4,4$ genotype, patients with epilepsy had mRNA levels that were greater than those of control patients (B). By Western blot (C), the relative levels of IL-1 $\alpha$ protein from epilepsy patients with APOE $\varepsilon 3,3$ were four-fold higher $(51 \pm 29)$ than those from either epilepsy patients with $A P O E \varepsilon 4,4$ genotype ( $8.6 \pm 4.3)$ or those of neurologically normal controls (6.3 $\pm 1.2 ; P=0.01$ for all comparisons) (D). These elevations in both IL-1 $\alpha$ mRNA and protein levels were accompanied by an increase in $\beta$ APP expression (E) that was limited to APOE $\varepsilon 3,3$ patients (APOE $\varepsilon 3,3=42 \pm 11$ vs APOE $\varepsilon 4,4$ $=20 \pm 11$ and control $=21 \pm 7 ; P=0.03$ for all comparisons) (F).

neurologically normal controls. In contrast to the epilepsy-associated increase in IL- $1 \alpha$ mRNA in patients of both genotypes, IL-1 $\alpha$ protein measured by Western blot showed much greater elevation of IL-1 $\alpha$ protein in $A P O E \varepsilon 3,3$ patients than that in APOE \&4,4 patients (Figure 4C). The increased IL-1 $\alpha$ expression in $A P O E$ $\varepsilon 3,3$ patients was approximately four-fold that of $A P O E$ $\varepsilon 4,4$ patients $(A P O E \varepsilon 3,3=51 \pm 29$ vs $A P O E \& 4,4=9 \pm$ 4; control $6 \pm 1 ; P<0.01$ ) (Figure 4D). These elevations in the levels of both IL-1 $\alpha$ mRNA and protein were accompanied by an $A P O E \& 3,3$ genotype-specific increase in $\beta$ APP expression in epilepsy patients compared to controls $(A P O E \varepsilon 3,3=42 \pm 11$ vs $A P O E \varepsilon 4,4=$ $20 \pm 11$; and control $=21 \pm 7 ; P=0.03$ ) (Figure 4E, F).

\section{$A \beta$ and $A p o E$ deposition relative to $A P O E$ genotype}

We found $\mathrm{A} \beta$ neuritic plaques in 13 of 52 APOE $\varepsilon 3,3$ patients, including one who was only 17 years old; one of the $7 A P O E \& 4,4$ patients had plaques; the youngest, 10 years of age (Figure 5A-C). For this one $A P O E \varepsilon 4,4$ patient, the number of plaques observed was 17 , which was similar to that found in four $A P O E \varepsilon 3,3$ patients who had $A \beta$ plaques, numbering $11,15,14$ and 16 . Interestingly, the $A \beta$ plaque phase in the one $A P O E \& 4,4$ patient was dense core neuritic while the plaques in $A P O E \varepsilon 3,3$ patients did not have dense cores. With our limited number of patients with $A P O E \varepsilon 4,4$ genotype, it is not possible to say whether a specific $A P O E$ genotype is associated with either a higher probability of having plaques or a genotype-related earlier age of onset for such $A \beta$ plaques. However, epilepsy was associated with an increased probability of $A \beta$ plaque development at a very early age. All $A \beta$ plaques observed contained ApoE deposits as well as ApoE-immunoreactive neurites, without regard to age or gender.

Neuronal expression of ApoE is related to APOE genotype In addition to ApoE immunoreactivity in $A \beta$ plaques and in $A \beta$ plaque-associated neurites in tissue from epilepsy, ApoE expression was also evident in neurons in all regions examined without regard to the presence of $A \beta$ plaques. Semi-quantitative ApoE immunofluorescence intensity in neuronal somas was elevated in those with $A P O E \& 3,3$ genotype relative to those with $A P O E$ $\varepsilon 4,4$ genotype $(A P O E \varepsilon 3,3=10 \pm 1$ vs $A P O E \varepsilon 4,4=8.3$ $\pm 0.8 ; P<0.05$ ) (Figure 5D). This modest elevation in immunofluorescence intensity was paralleled in $A P O E$ $\varepsilon 3,3$ patients by a marked increase in relative tissue levels (Figure $5 \mathrm{E})$ of ApoE $(A P O E \varepsilon 3,3=7.19 \pm 1.75$ vs $A P O E \& 4,4=1.04 \pm 0.06$, and control $=1.27 \pm 0.38 ; P<$ 0.001 ) (Figure $5 \mathrm{~F}$ ). 
A

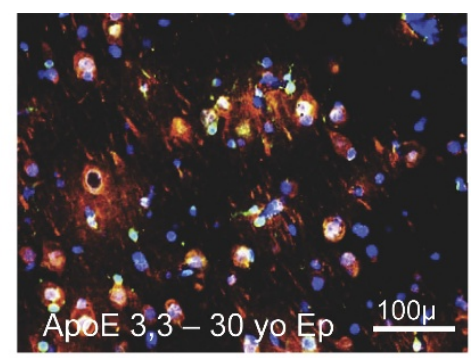

C

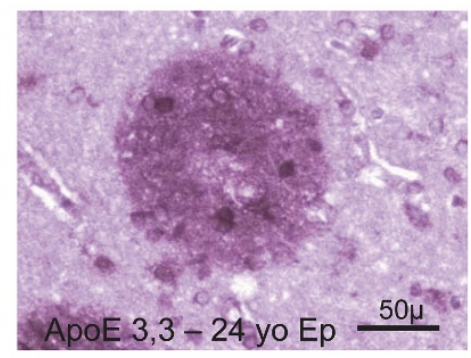

E

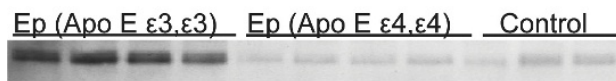

$\begin{array}{lllllllllll}38 & 57 & 24 & 44 & 10 & 22 & 34 & 50 & 97 & 93 & 59\end{array}$

$2,2 \quad 3,3 \quad 3,3$
B

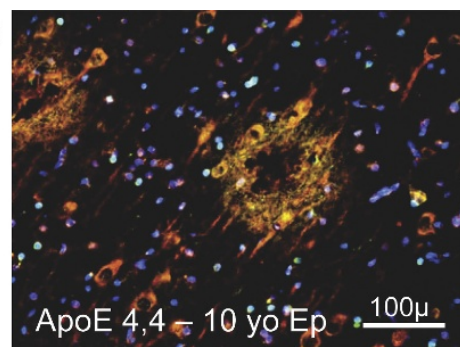

D
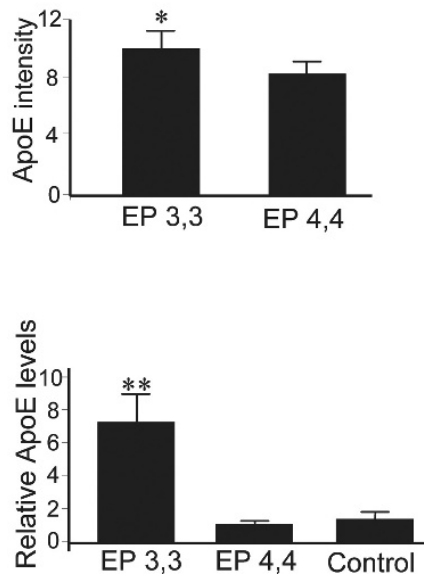

Figure 5 ApoE tissue levels and $A \beta$ plaques in epilepsy relative to APOE genotype Multiple $A \beta$ (green) and ApoE (red) immunofluorescent plaques were present in 15 of the 52 APOE $\varepsilon 3,3$ patients (colocalization of $A p o E$ and $A \beta$ is yellow). (A)

Representative section from a 30-year-old APOE $\varepsilon 3,3$ patient. (B) Representative section from the one of seven APOE $\varepsilon 4,4$ patients who had AB plaques. (C) Both the shape and distribution to $A \beta$ plaques were similar without regard to APOE genotype as shown in a 24-year-old $A P O E \varepsilon 3,3$ patient illustrated by light microscopy (ApoE immunoreactivity (brown); $A \beta$ (magenta)). (D) ApoE immunofluorescent intensity was greater in tissue from those with $A P O E \varepsilon 3,3$ than in those with $A P O E \varepsilon 4,4$ genotype (APOE $\varepsilon 3,3=10 \pm 1$ vs APOE $\varepsilon 4,4=8.3 \pm 0.8 ; P=0.04$ ). This difference in intensity was paralleled by increased relative tissue levels of ApoE (E) (APOE $\varepsilon 3,3=7.19 \pm 1.75$ vs APOE $\varepsilon 4,4=1.04 \pm 0.06$, and control $=1.27$ $\pm 0.38 ; P<0.001$ for all comparisons) (F).

\section{Synaptophysin and phosphorylated tau expression relative to $A P O E$ genotype}

The synaptic density in photomicrographs from each of the patient groups appeared to be similar, with somewhat higher levels in those with $A P O E \varepsilon 3,3$ genotype, as measured by relative levels of synaptophysin $(A P O E \varepsilon 3,3$ $=3.57 \pm 0.76$ vs $A P O E \& 4,4=2.62 \pm 0.80$ vs controls $=$ $2.41 \pm 0.36 ; P=0.11$ ) (Figure 6A. B). As previously reported [14], phosphorylated tau immunofluorescent labeling was not elevated in any of our patients regardless of age or $A p o E$ genotype. This was confirmed by Western blot analysis; the bands were faint and the measured levels were low (Figure 6C, D).

\section{Discussion}

Tissues from patients undergoing temporal lobectomies for drug-resistant epilepsy reveal APOE genotype-specific links between glial and neuronal stress responses. This influence of $A P O E$ genotype in epilepsy appears to occur without regard to gender or age at the time of surgery. Glial activation with overexpression of IL-1 is well known to induce neuronal expression of two ADassociated, stress-related proteins ApoE and $\beta$ APP $[10,15]$. Connections among APOE genotype, epilepsy and $\mathrm{AD}$ have been drawn, but mechanisms by which the $A P O E \& 4,4$ genotype heightens intensity of neuronal damage or, conversely, how the APOE $\varepsilon 3,3$ genotype may act to promote neuronal resilience remains unclear.

The numbers of neurons in temporal lobe tissue of our epilepsy patients who were either $A P O E \varepsilon 3,3$ or $A P O E \& 4,4$ genotype were similar, but there were striking differences in the indicators of degeneration in neurons, as neurons from patients with $A P O E \& 3,3$ were larger, appeared more normal morphologically, and had less DNA damage. These findings suggest that neurons from individuals with the $A P O E \varepsilon 3,3$ genotype are better able to mount appropriate and more liberal repair responses to the damaging hyperexcitability of epilepsy than are their $A P O E \varepsilon 4,4$ counterparts, suggesting that $A P O E \varepsilon 3$, but not $A P O E \& 4$, alleles confer resilience to 


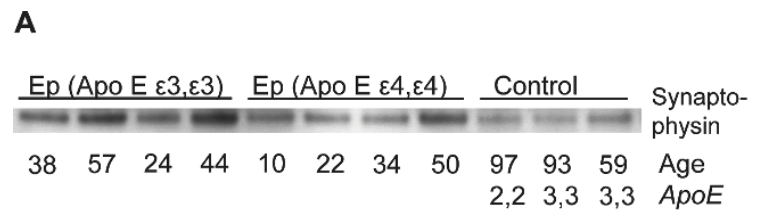

C

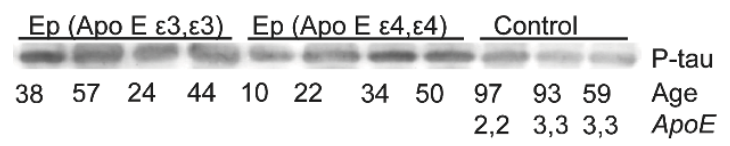

E

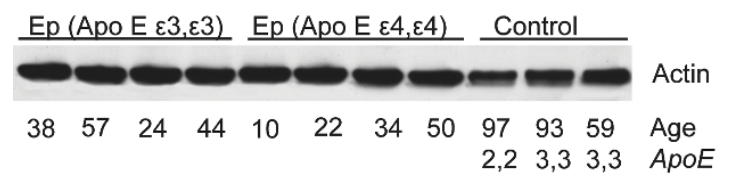

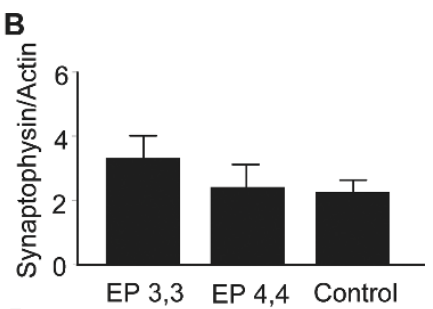

D

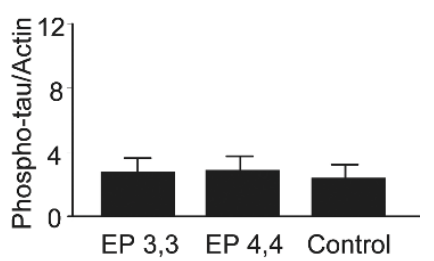

$\mathbf{F}$

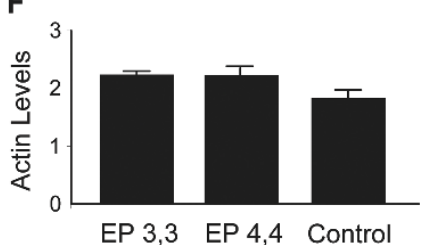

Figure 6 Synaptophysin, phosphorylated tau and actin in epilepsy relative to APOE genotype An impression of similar synaptic densities in photomicrographs from each of the patient groups was confirmed by western blot analysis for the relative levels of synaptophysin compared to actin (APOE $\varepsilon 3,3=\mathbf{3 . 5 7} \pm 0.76$ vS APOE $\varepsilon 4,4=2.62 \pm 0.8$ vs controls $=2.41 \pm 0.36 ; P=0.11$ for all comparisons) (A and B). Western blot analysis of phosphorylated tau (P-tau) (C) showed no differences with regard to genotype (D). Western blot analysis of actin (E) was used to assess specific protein levels of IL-1 $\alpha, \beta$ APP, ApoE, synaptophysin, and P-tau relative to actin. Actin expression was not different with regard to APOE genotype or levels of actin in tissue from controls (F).

host neurons no matter the type of injury. This might be inferred from studies reporting earlier onset of epilepsy, especially following traumatic brain injury in patients with $A P O E \& 4$ alleles [16,17].

Our finding of elevated synthesis of IL-1 $\alpha$ in the temporal lobe of epilepsy patients compared to that in neurologically normal controls confirms an earlier report [4] of elevated IL-1 $\alpha$ protein and accompanying glial activation and other neuroinflammatory changes. However, the association made here between this overexpression of IL- $1 \alpha$ and beneficial effects toward enhancing neuronal resilience may help to explain, at least in part, why IL- $1 \alpha$ elevation is necessary for neuronal survival in dorsal root ganglion cell cultures [18]. Moreover, evidence of greater neuron sparing in epilepsy patients with $A P O E \varepsilon 3,3$ than $A P O E \& 4,4$ genotype may be a case in point for genetic variation favoring typical, evolutionarily old, acute phase responses [19] of neurons to adverse stimuli, which includes elevation of IL-1 $\alpha, \beta$ APP and ApoE expression [10] and protection against DNA fragmentation.

The original report of a role for IL-1 $\alpha$ in induction, maintenance and propagation of axonal sprouting in an experimental model of neurodegeneration [20] and an association between glial activation and sprouting of mossy fibers in epilepsy [21] is supported by our finding of somewhat elevated synaptophysin levels in combination with high numbers of neuron-associated, IL- $1 \alpha$ immunoreactive microglia and elevation of IL- $\alpha$ mRNA and protein levels. In addition, the apparent elevation of synaptophysin expression noted here in immunoblots of neural tissue proteins from our epilepsy patients compared to that from our neurologically and neuropathologically normal controls may be explained if, as previously noted in animal models of epilepsy, [21,22] there is neuronal sprouting in epilepsy patients.

Amyloid- $\beta$ plaques are obligatory for the diagnosis of $\mathrm{AD}$ and are most prominent in the elderly. In contrast, $\mathrm{A} \beta$ plaques in epilepsy, as shown here and as reported in about $10 \%$ of cases [2], are evident at young ages. For instance among our patients, a 10-year-old patient had A $\beta /$ ApoE immunoreactive plaques in a distribution similar to that noted in temporal lobes of Alzheimer patients. The presence of plaques at such early ages suggests that they are harbingers of impending neurodegeneration and AD. Although the number of plaques was similar in tissue from our patients without regard to $A P O E$ genotype, in our one $A P O E \& 4,4$ patient the developmental phase of $\mathrm{A} \beta$ plaques appeared to be advanced relative to those observed in our $A P O E \& 3,3$ patients - our APOE \&4,4 
patient had dense core neuritic $A \beta$ plaques, while such dense core plaques were not found among the plaques observed in our APOE $\varepsilon 3,3$ patients. This observation is consistent with the possibility that the phase of $\mathrm{A} \beta$ plaque progression is accelerated in those with $A P O E \& 4,4$ genotype and supports the findings of Marz et al., regarding the role of $A P O E$ genotype in the onset of $\mathrm{A} \beta$ plaque pathology and the presence of dense core plaques [23].

Alzheimer's patients are more likely to have seizures than are those in the general population [24]. This, together with our findings and the previously reported preferential occurrence of seizures in younger Alzheimer patients [25], supports a suggested relationship between the high levels of $A \beta$ in the brains of epilepsy patients [26] and increased risk for development of AD. These findings are consistent with the idea that AD-related neuronal stress and its sequelae, including excess neuronal $\beta$ APP and ApoE expression and glial activation with elevated cytokine expression, combined with known IL-1-driven elevation of neuronal and glial glutamate production contribute to the hyperexcitability of epilepsy [9]. Moreover, these findings, together with evidence from our epilepsy patients, suggest that ApoE genotype, in particular $A P O E$ $\varepsilon 4,4$ may favor rapidity of disease progression as well as risk for associated memory disturbances. Conversely, a better understanding of mechanisms by which $A P O E \varepsilon 3$ alleles confer the neuronal protection shown here may facilitate development of therapeutic strategies toward improving outcomes for epilepsy patients, as well as patients with other neuronal distresses.

\section{Conclusion}

The most striking aspect of this work is that our findings illuminate the "other" side of the $A P O E$ genotypic equation in showing ways in which $A P O E \varepsilon 3$ alleles may act to preserve important aspects of neuronal abilities to mount appropriate, beneficial stress responses to hyperexcitability, neuroinflammation and neuronal DNA damage. In addition, our findings are consistent with the idea that as neurons with $A P O E \& 4$ alleles are less resilient to the chronic excitation of epilepsy and more susceptible to DNA damage, patients who carry $A P O E$ $\varepsilon 4$ alleles are at greater risk of developing $\mathrm{AD}$ than are those with $A P O E \& 3$ alleles. Moreover, our findings are in accord with the possibility that epilepsy-related neuropathological changes, such as increases in the levels of $\mathrm{A} \beta$ peptides, contribute to propagation of epileptiform activity in adjacent neurons and furtherance of neuropathological changes and the risk of AD [26].

\section{Abbreviations}

AB: amyloid $\beta$; AD: Alzheimer's disease; ApoE: apolipoprotein E; au: arbitrary units; $\beta$ APP: amyloid $\beta$ precursor protein; IL: interleukin; TUNEL, terminal deoxynucleotidyl transferase dUTP nick end labeling.

\section{Acknowledgements}

The authors are especially grateful to the patients who shared with us: without them, this work could not have been done. We would also like to thank Dr. John L. Greenfield and Dr. Steven W. Barger for their helpful advice, and Dr. Ling Liu, JoAnn Biedermann and Richard A. Jones for their skillful technical assistance and advice. This work was supported in part by NIH-NIA AG12411, the Windgate Foundation, the Donald W. Reynolds

Foundation, and the Grand Aerie Fraternal Order of the Eagles, Auxiliary \#60.

\section{Author details}

'Donald W. Reynolds Department of Geriatrics, Reynolds Institute on Aging, 629 Jack Stephens Drive, Little Rock, AR 72205, USA. ${ }^{2}$ Geriatric Research Education Clinical Center, Central Arkansas Veterans Healthcare Systems, 4300 West Seventh Street, Little Rock, AR 72205, USA. ${ }^{3}$ Department of Neurobiology and Developmental Sciences, University of Arkansas College of Medicine, 4300 Markham Street, Little Rock, AR 72205, USA. ${ }^{4}$ Department of Pathology, University of Toledo Health Sciences Campus, 3000 Arlington Avenue, Toledo, OH 43614, USA. ${ }^{5}$ Department of Neurosurgery, University of Tennessee Health Sciences Center, 50 N Dunlap St, Memphis, TN 38163 USA.

\section{Authors' contributions}

OA conducted and helped with the design of all experiments, with interpretation of the data and writing of the manuscript. REM conducted all neuropathological evaluations and contributed to interpretation of results and writing of the manuscript. FB was the neurosurgeon who provided the tissue and reviewed the writing. WSTG designed the study with OA, verified and helped with interpretation of the data, and contributed to the writing All authors read and approved the final manuscript.

\section{Competing interests}

The authors declare that they have no competing interests.

Received: 11 December 2011 Accepted: 13 April 2012

Published: 13 April 2012

\section{References}

1. Gouras GK, Relkin NR, Sweeney D, Munoz DG, Mackenzie IR, Gandy S: Increased apolipoprotein E epsilon 4 in epilepsy with senile plaques. Ann Neurol 1997, 41:402-404.

2. Mackenzie IR, Miller LA: Senile plaques in temporal lobe epilepsy. Acta Neuropathol (Berl) 1994, 87:504-510.

3. Griffin WS, Yeralan O, Sheng JG, Boop FA, Mrak RE, Rovnaghi CR, Burnett BA, Feoktistova A, Van Eldik LJ: Overexpression of the neurotrophic cytokine $\mathrm{S} 100$ beta in human temporal lobe epilepsy. $J$ Neurochem 1995, 65:228-233.

4. Sheng JG, Boop FA, Mrak RE, Griffin WS: Increased neuronal beta-amyloid precursor protein expression in human temporal lobe epilepsy: association with interleukin-1 alpha immunoreactivity. J Neurochem 1994, 63:1872-1879

5. Gahring LC, White HS, Skradski SL, Carlson NG, Rogers SW: Interleukin1alpha in the brain is induced by audiogenic seizure. Neurobiol Dis 1997, 3:263-269.

6. Griffin WS, Stanley LC, Ling C, White L, MacLeod V, Perrot LJ, White CL, Araoz C: Brain interleukin 1 and S-100 immunoreactivity are elevated in Down syndrome and Alzheimer disease. Proc Natl Acad Sci USA 1989, 86:7611-7615.

7. Barger SW, Harmon AD: Microglial activation by Alzheimer amyloid precursor protein and modulation by apolipoprotein E. Nature 1997, 388:878-881.

8. Sheng JG, Ito K, Skinner RD, Mrak RE, Rovnaghi CR, Van Eldik LJ, Griffin WS: In vivo and in vitro evidence supporting a role for the inflammatory cytokine interleukin-1 as a driving force in Alzheimer pathogenesis. Neurobiol Aging 1996, 17:761-766.

9. Liu L, Aboud O, Jones RA, Mrak RE, Griffin ST, Barger SW: Apolipoprotein E expression is elevated by interleukin 1 and other interleukin 1 -induced factors. J Neuroinflammation 2011, 8:175.

10. Barger SW, DeWall KM, Liu L, Mrak RE, Griffin WS: Relationships between expression of apolipoprotein E and beta-amyloid precursor protein are altered in proximity to Alzheimer beta-amyloid plaques: potential explanations from cell culture studies. J Neuropathol Exp Neurol 2008, 67:773-783. 
11. Teasdale GM, Murray GD, Nicoll JA: The association between APOE epsilon4, age and outcome after head injury: a prospective cohort study. Brain 2005, 128:2556-2561.

12. Thal DR, Capetillo-Zarate E, Del Tredici K, Braak H: The development of amyloid beta protein deposits in the aged brain. Sci Aging Knowledge Environ 2006, 2006:re1.

13. Li Y, Wang J, Sheng JG, Liu L, Barger SW, Jones RA, Van Eldik LJ, Mrak RE, Griffin WS: S100 beta increases levels of beta-amyloid precursor protein and its encoding mRNA in rat neuronal cultures. J Neurochem 1998, 71:1421-1428.

14. Braak E, Strotkamp B, Braak H: Parvalbumin-immunoreactive structures in the hippocampus of the human adult. Cell Tissue Res 1991, 264:33-48.

15. Vezzani A, Balosso S, Ravizza T: The role of cytokines in the pathophysiology of epilepsy. Brain Behav Immun 2008, 22:797-803.

16. Miller MA, Conley Y, Scanlon JM, Ren D, llyas Kamboh M, Niyonkuru C, Wagner AK: APOE genetic associations with seizure development after severe traumatic brain injury. Brain Inj 2010, 24:1468-1477.

17. Briellmann RS, Torn-Broers $Y$, Busuttil BE, Major BJ, Kalnins RM, Olsen M, Jackson GD, Frauman AG, Berkovic SF: APOE epsilon4 genotype is associated with an earlier onset of chronic temporal lobe epilepsy. Neurology 2000, 55:435-437.

18. Brenneman DE, Hill JM, Glazner GW, Gozes I, Phillips TW: Interleukin-1 alpha and vasoactive intestinal peptide: enigmatic regulation of neuronal survival. Int J Dev Neurosci 1995, 13:187-200.

19. Rosen DR, Martin-Morris L, Luo LQ, White K: A Drosophila gene encoding a protein resembling the human beta-amyloid protein precursor. Proc Natl Acad Sci USA 1989, 86:2478-2482

20. Ho A, Blum M: Induction of interleukin-1 associated with compensatory dopaminergic sprouting in the denervated striatum of young mice: model of aging and neurodegenerative disease. J Neurosci 1998, 18:5614-5629.

21. Proper EA, Oestreicher AB, Jansen GH, Veelen CW, van Rijen PC, Gispen WH, de Graan PN: Immunohistochemical characterization of mossy fibre sprouting in the hippocampus of patients with pharmaco-resistant temporal lobe epilepsy. Brain 2000, 123:19-30.

22. Lew FH, Buckmaster PS: Is there a critical period for mossy fiber sprouting in a mouse model of temporal lobe epilepsy? Epilepsia 2011, $52: 2326-2332$

23. Marz W, Scharnagl H, Kirca M, Bohl J, Gross W, Ohm TG: Apolipoprotein E polymorphism is associated with both senile plaque load and Alzheimer-type neurofibrillary tangle formation. Ann N Y Acad Sci 1996, 777:276-280.

24. Bernardi S, Scaldaferri N, Vanacore N, Trebbastoni A, Francia A, D'Amico A, Prencipe M: Seizures in Alzheimer's disease: a retrospective study of a cohort of outpatients. Epileptic Disord 2010, 12:16-21.

25. Scarmeas N, Honig LS, Choi H, Cantero J, Brandt J, Blacker D, Albert M, Amatniek JC, Marder K, Bell K, Hauser WA, Stern Y: Seizures in Alzheimer disease: who, when, and how common? Arch Neurol 2009, 66:992-997.

26. Palop JJ, Mucke L: Epilepsy and cognitive impairments in Alzheimer disease. Arch Neurol 2009, 66:435-440.

\section{Pre-publication history}

The pre-publication history for this paper can be accessed here: http://www.biomedcentral.com/1741-7015/10/35/prepub

doi:10.1186/1741-7015-10-35

Cite this article as: Aboud et al:: Apolipoprotein epsilon 3 alleles are associated with indicators of neuronal resilience. BMC Medicine 2012 10:35.

\section{Submit your next manuscript to BioMed Central and take full advantage of:}

- Convenient online submission

- Thorough peer review

- No space constraints or color figure charges

- Immediate publication on acceptance

- Inclusion in PubMed, CAS, Scopus and Google Scholar

- Research which is freely available for redistribution 